\title{
CASE REPORT \\ Delayed spinal epidural hematoma following spinal anesthesia, far from needle puncture site
}

\author{
A Makris $^{1}$, E Gkliatis $^{1}$, M Diakomi $^{1}$, I Karmaniolou $^{2}$ and A Mela ${ }^{1}$
}

\section{Study design: Case report.}

Objectives: We report a case of spinal epidural hematoma (SEH) that appeared on the third postoperative day after lumbar spinal anesthesia, far from the needle puncture site. Possible mechanisms and etiological relation to patient's risk factors as well as diagnosis and management of SEH are briefly discussed.

Setting: Asklepieion General Hospital of Voula, Athens, Greece.

Methods and results: A 64-year-old woman underwent an uneventful total knee arthroplasty operation under a spinal anesthetic. A lumbar puncture was performed in the L2-L3 interspace, that was atraumatic and successful on the first attempt. The operation was uneventful. On the third postoperative day, the patient developed a SEH that expanded from C2 to T3 levels. She was presented with bilateral shoulder pain, muscle weakness of the upper extremities with normal sensation, followed by paraparesis. The magnetic resonance imaging (MRI) revealed a large vascular malformation, partially ruptured forming a hematoma compressing the spinal cord toward the vertebral bodies The patient was treated conservatively and full recovery was achieved.

Conclusion: The possibility of SEH must be considered whenever neurological symptoms occur in the postoperative period, especially after a neuraxial blockade. The causes are multiple, a not-known lesion predisposing to bleeding and hematoma formation may preexist and the anesthetic technique can be directly or indirectly connected to this complication. MRI is the preferred diagnostic method.

Spinal Cord (2014) 52, S14-S16; doi:10.1038/sc.2013.174; published online 21 January 2014

Keywords: spinal epidural hematoma; spinal anesthesia; epidural vascular malformation

\section{INTRODUCTION}

Spinal anesthesia is a well-established ordinary practice for patients undergoing orthopedic surgery. Spinal epidural hematoma (SEH) represents a rare, but potentially devastating complication of spinal anesthesia with an incidence, according to a recent 10-year closed claims analyses, of $1: 775000 .^{1}$ After obtaining patient's written consent, we report a case of SEH, far from the spinal needle puncture site, on the third postoperative day.

\section{CASE PRESENTATION}

A 64-year-old woman, with BMI of $22.3 \mathrm{~kg} \mathrm{~m}^{-2}$, was scheduled for left total knee replacement. Her medical history was unremarkable. Her laboratory investigations, including renal function, platelet count and coagulation tests (activated partial thromboplastin time and international normalized ratio), were within normal range. She had spinal anesthesia, which is commonly preferred in our department over epidural mainly due to its rapid onset of surgical anesthesia, in the sitting position through a median approach with a 25-gauge Whitacre needle (Vygon, Ecouen, France) in the L2/L3 space. The technique was atraumatic and successful on first attempt. No paresthesia was elicited, clear cerebrospinal fluid was obtained and $3 \mathrm{ml}$ bupivacaine $0.5 \%$ was injected intrathecally. Within $12 \mathrm{~min}$, complete motor block of the lower extremities was achieved and the sensory block, evaluated using the pinprick test, was identified at the T8 level bilaterally. The surgical procedure was uneventful and the block was fully reversed $3 \mathrm{~h}$ later. She was mobilized on the same day. Prophylactic anticoagulation (subcutaneous bemiparin 3500 IU per day) was started the next day.

On the third postoperative day at 1200 hours ( $4 \mathrm{~h}$ after bemiparin administration), she complained of acute onset pain in both shoulders and upper extremities. Within $20 \mathrm{~min}$, the pain increased and shortly after, paraparesis emerged. Blood pressure was 180/ $90 \mathrm{~mm} \mathrm{Hg}$ and her electrocardiogram was unremarkable. Clinical examination revealed sensory loss below T10, flaccid paralysis of the lower extremities (muscle strength: grade 0) and muscle weakness of the upper extremities (muscle strength: grade 3 for forearm flexion, grade 2 for elbow extension, grade 0 for finger flexion-extension) with normal sensation. New clotting tests were normal. A magnetic resonance imaging (MRI) was performed at 1300 hours, which revealed a vascular malformation from $\mathrm{C} 2$ to $\mathrm{T} 3$, partially ruptured, compressing the spinal cord, mostly at C6/C7 and C5/C6 levels, where small disc herniations were additionally present (Figure 1). Since the clinical presentation was gradually improving after the MRI, conservative treatment was decided, using methylprednisolone $16 \mathrm{mg}$ three times daily, which was continued for 10 days after neurological status was restored. At 2000 hours, sensation was normal in upper and lower extremities and at 0200 hours motor activity of the lower extremities was restored. Following diagnosis, bemiparin was discontinued and pneumatic calf compression devices were used instead. She was mobilized 2 days later and was discharged 9 days later without 

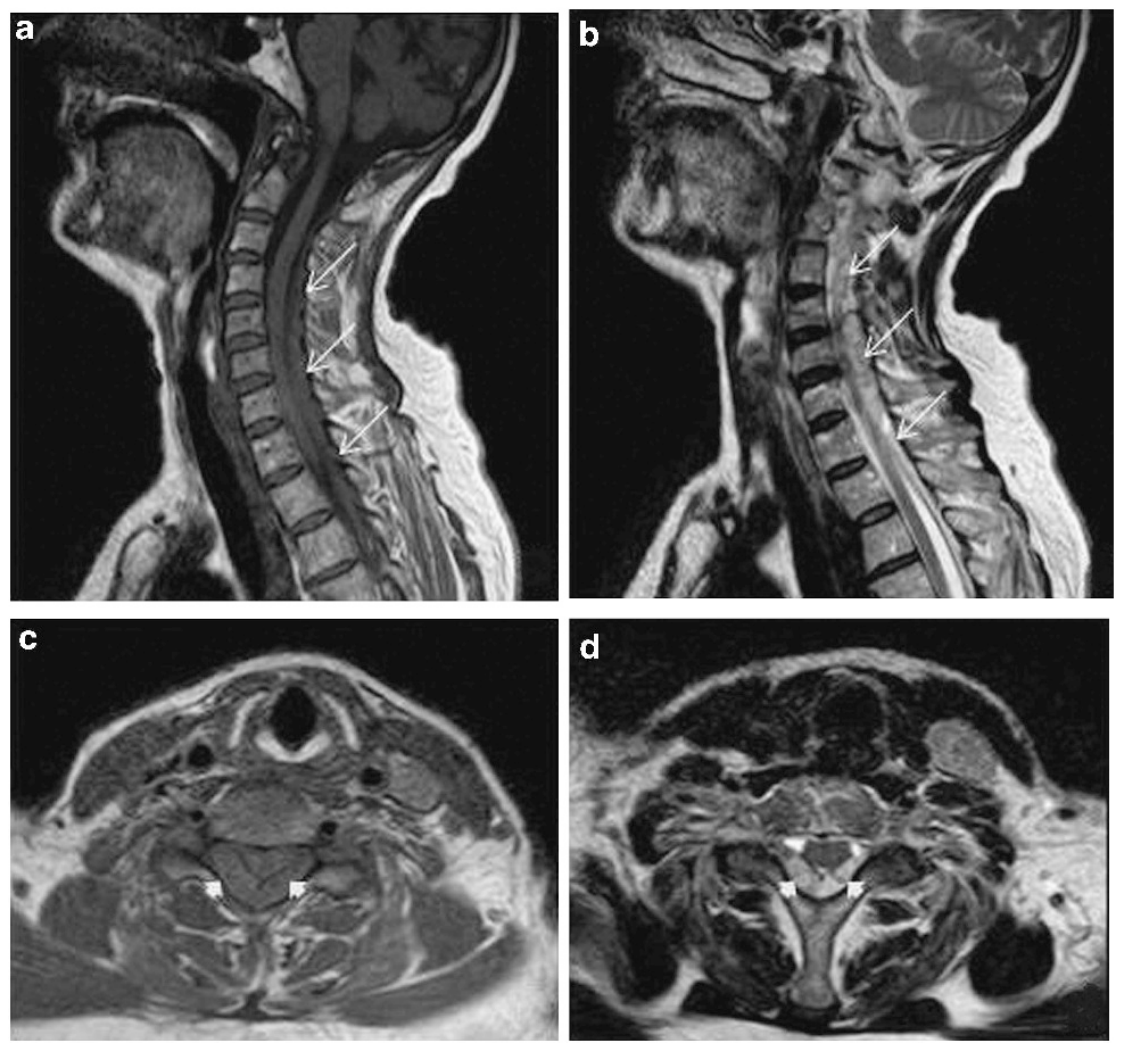

Figure 1 Early MRI. (a) T1-weighted sagittal image showing an intermediate signaling mass, corresponding to an epidural hematoma (arrows). (b) T2-weighted image showing a hyperintensive signaling mass depicting an abnormal clustering of vessels corresponding to a vascular malformation (arrows) and the hematoma. (c, d) T1 and T2-weighted axial images of the upper cervical spine showing the epidural hematoma (arrows) compressing posteriorly the spinal cord toward the vertebral bodies.

any symptoms. Follow-up was scheduled in order to reevaluate the patient and perform a selective spinal angiography that would be needed to confirm the diagnosis, allow classifying of the venous malformation and discuss further endovascular or surgical therapeutic possibilities but the patient did not attend the appointment.

\section{DISCUSSION}

A SEH may be either spontaneous or secondary to trauma, coagulation disorders or regional anesthetic techniques. Risk factors include advanced age, female gender, traumatic and multiple attempts at puncture for neuraxial anesthesia, vascular malformations, anticoagulation therapy and arterial hypertension. ${ }^{2}$ Regarding neuraxial techniques, the level of the hematoma is usually the level of puncture or up to the highest level of catheter insertion. ${ }^{3}$ Hemorrhagic complications, far from needle puncture site, attributed to anesthesia, have been reported mainly as cerebral subdural hematomas, where the possible mechanism is the caudal shift of intracranial structures due to low CSF pressure causing traction on dural veins with subsequent bleeding. ${ }^{3,4}$

The etiological relation to bemiparin cannot be excluded, as onset of symptoms corresponds to the timing of its maximal plasma antiXa activity (2-6h). The interval between initiation of low molecular weight heparin and onset of neurological dysfunction due to hematoma ranges between $15 \mathrm{~h}$ and 3 days, which is in agreement with our finding. On the other hand, the possibility of vessel damage during spinal anesthesia has been reported, but is difficult to document. In our case, multifactorial etiology is more likely, including vascular malformation and thromboprophylaxis, especially since the hematoma occurred on the third day after spinal anesthesia and on the second day after starting thromboprophylaxis, while mechanically induced vessel damage cannot be ruled out. The latter may be attributed to a caudal traction on the arachnoid matter and epidural venous plexus of cervical and thoracic regions secondary to loss of CSF after the lumbar puncture, causing stretching and tearing of the epidural veins. If an epidural anesthesia had been performed, this mechanical stress would have been avoided, unless an accidental dural puncture had occurred, but as we are not sure of which factor had a major role in the occurrence of the hematoma, it is difficult to exactly assess the degree of involvement of the anesthetic technique on the outcome.

Treatment of SEH includes either surgical or conservative measures. Conservative treatment with repeated neurologic examination was decided in our case, based on the gradual resolution of symptoms, after the MRI, which might be explained by the leakage of the fluid hematoma through the intervertebral foramina, relieving the pressure on the spinal cord. The dosage and duration of methylprednisolone treatment was as per the judgment and experience of the neurosurgeon and not as per any guidelines. Several cases of complete resolution have been described with conservative management and there is a growing body of evidence supporting it in selected cases. The majority of patients treated conservatively had already shown improvement during initial evaluation. ${ }^{5}$

\section{CONCLUSIONS}

The possibility of SEH should always be considered whenever neurological symptoms occur in the postoperative period, especially 
if neuraxial blockade has been performed. Detailed neurological examination should be carried out in any case of suspicion. MRI is the preferred diagnostic method and early neurosurgical consultation is imperative in order to decide on management. Conservative treatment may be considered in selected cases.

\section{DATA ARCHIVING}

There were no data to deposit.

\section{CONFLICT OF INTEREST}

The authors declare no conflict of interest.

\section{AUTHOR CONTRIBUTIONS}

AM and EG evaluated the patient and wrote the initial draft of the manuscript. MD contributed to the design of the manuscript and data interpretation.
IK made significant contribution to the literature research and editing of the manuscript. AM supervised the project.

1 Pitkänen MT, Aromaa U, Cozanitis DA, Förster JG. Serious complications associated with spinal and epidural anaesthesia in Finland from 2000 to 2009. Acta Anaesthesiol Scand 2013; 57: 553-564.

2 Kreppel D, Antoniadis G, Seeling W. Spinal hematoma: a literature survey with metaanalysis of 613 patients. Neurosurg Rev 2003; 26: 1-49.

3 Madhugiri VS, Singh M, Sasidharan GM, Roopesh Kumar VR. Remote spinal epidural haematoma after spinal anaesthesia presenting with a 'spinal lucid interval'. BMJ Case Rep (e-pub ahead of print 29 October 2012; doi:10.1136/bcr-2012-007258).

4 Amorim JA, Remígio DS, Damázio Filho O, de Barros MA, Carvalho VN, Valença MM. Intracranial subdural hematoma post-spinal anesthesia: report of two cases and review of 33 cases in the literature. Rev Bras Anestesiol 2010; 60: 344-349.

5 Groen RJ. Non-operative treatment of spontaneous spinal epidural hematomas: a review of the literature and a comparison with operative cases. Acta Neurochir 2004; 146: 103-110. 